\title{
PENGEMBANGAN INDEKS LITERASI PEGAWAI KEJAKSAAN NEGERI ACEH TENGAH MELALUI TEKNIK RESUME BUKU DIGITAL DALAM PENGUATAN KELEMBAGAAN DI ERA INDUSTRI 4.0 DAN SOCIETY 5.0
}

\author{
Yovandi Yazid ${ }^{1}$, Nazamuddin ${ }^{2}$, Muhammad Rizza ${ }^{3}$, Zainul Arifin ${ }^{4}$, Adenan Sitepu $^{5}$, Nur \\ Hidayat $^{6}$, Zulfikri MK ${ }^{7}$, Supinto ${ }^{8}$,Muhammad Jailani ${ }^{9}$,Muhammad Hasyimsyah Batubara ${ }^{10}$ \\ 1,2,3,4,5,6,7,8,9 Kejaksaan Negeri Aceh Tengah, Aceh, Indonesia, ${ }^{10}$ IAIN Takengon, Aceh, Indonesia \\ email: muhammmad.hasyimsyahbatubara@gmail.com
}

\begin{abstract}
This service activity in collaboration with the Central Aceh Prosecutor's Office is the development of a literacy index for the Central Aceh District Attorney's Office through digital book resume techniques in institutional strengthening in the industrial 4.0 and social 5.0 era. Based on observations and interviews, there are 4 main problems faced by partners, including: (1) limited time, (2) focusing on physical books in the library, (3) lack of information about digital books on digital library portals (4) lack of interest in reading books from the beginning to the end. Based on these problems, solutions were offered: (1) assistance on the ease of using a short time to read digital books, (2) suggesting reading digital books (3) assistance in introducing digital library sites, (4) mentoring and workshops on how to resume books bold digital to 5-15 pages. Specific targets and outcomes that will be produced: (1) build reading habits even though time is limited, (2) don't focus on physical books and can switch to digital format books, (3) build the habit of visiting digital libraries, (4) the ability to use a digital book resume application to get the gist of a book. The method of implementing the service program will be carried out in stages, continuously, and comprehensively through mentoring and workshop methods.
\end{abstract}

Keywords: Improvement, Literacy, Digital Book, Book Resume

\begin{abstract}
Abstrak: Kegiatan pengabdian yang bekerjasama dengan Kejaksaan Aceh Tengah ini adalah pengembangan indeks literasi pegawai Kejaksaan Negeri Aceh Tengah melalui teknik resume buku digital dalam penguatan kelembagaan di era industri 4.0 dan sosiety 5.0. Berdasarkan observasi dan wawancara terdapat 4 masalah utama yang dihadapi mitra, antara lain: (1) waktu yang terbatas, (2) terfokus pada buku fisik yang ada di perpustakaan, (3) kurang informasi tentang buku-buku digital di portal perpustakaan digital (4) kurangnya minat membaca buku dari halaman awal hingga akhir. Berdasarkan permasalahan tersebut ditawarkan solusi: (1) pendampingan tentang kemudahan menggunakan waktu yang singkat untuk membaca buku digital, (2) menyarankan membaca buku-buku digital (3) pendampingan memperkenalkan situssitus perpustakaan digital, (4) pendampingan dan workshop bagaimana meresume buku digital yang tebal menjadi 5-15 halaman. Target khusus dan luaran yang akan dihasilkan: (1) membangun kebiasaan membaca walaupun waktu terbatas, (2) jangan terfokus dengan buku fisik dan bisa beralih ke buku-buku format digital, (3) membangun kebiasaan mengunjungi perpustakaan-perpustakaan digital, (4) kemampuan menggunakan aplikasi resume buku digital sehingga mendapatkan intisari satu buku. Metode pelaksanaan program pengabdian akan dilakukan secara bertahap, berkelanjutan, dan komprehensif yang dilaksanakan melalui metode pendampingan dan workshop.
\end{abstract}

Kata Kunci: Peningkatan, Literasi, Buku Digital, Resume Buku

\section{Pendahuluan}

Dewasa ini kecakapan literasi individu atau kelompok masyarakat merupakan tuntutan yang tidak dapat dihindari oleh siapapun dalam menghadapi era revolusi 4.0 dan society 5.0. Indeks literasi masyarakat Indonesia yang dirilis oleh UNESCO dalam publikasi CNN Indonesia menyebutkan dari 61 negara yang dijadikan sampel penelitian, Finlandia menduduki peringkat pertama dengan tingkat literasi tinggi hampir mencapai 
$100 \%$ masyarakatnya melek literasi, posisi dengan angka literasi rendah terakhir diisi oleh Botswana, sedangkan Indonesia berada di peringkat 60, masih kalah dengan Thailand di peringkat 59. Data ini menunjukkan kenyataan dan fakta yang cukup membuat miris dengan persentase minat baca masyarakat Indonesia tergolong rendah, yaitu hanya $0,01 \%$ atau 1 berbanding 10.000 orang (Literasi Indonesia, 2017 dalam Batubara, 2018). Rendahnya literasi masyarakat ini secara langsung akan memberikan dampak terhadap kesiapan untuk bersaing dengan masyarakat dunia yang tidak ada sekat seperti sekarang ini. Padahal kesiapan akan literasi (literasi baca dan tulis, literasi numerasi, literasi sains, literasi keuangan, literasi digital, literasi budaya dan kewarganegaraan) yang digandeng dengan karakter (karakter moral: iman, takut akan tuhan, jujur, rendah hati, karakter kinerja: ulet, kerja keras, tangguh, tidak mudah menyerah, tuntas) dan dilengkapi dengan kompetensi (berpikir kritis, kreatif, komunikatif, kolaborasi atau kerjasama) merupakan perisai yang sangat dibutuhkan untuk membantu membentengi kedaulatan bangsa dari gempuran masyarakat dunia dalam kancah ekonomi, sosial, politik, hukum dan sektor kehidupan lainnya di negara kita (Batubara, 2018).

Untuk meningkatkan minat baca masyarakat dan lebih jauh meningkatkan indeks literasi di Indonesia dibutuhkan peran segenap komponen, baik itu masyarakat perorangan, kelompok, lembaga, dan usur-unsur pemerintah yang ada guna melakukan sosialisasi pentingnya menumbuhkan dan memposisikan kegiatan membaca sebagai bagian dari kebutuhan diri. Di era sekarang membaca tidak harus dengan menggunakan buku fisik, namun bisa dilakukan dengan smartphon masing-masing yang dimiliki masyarakat. Sehingga tidak ada alasan untuk tidak meningkatkan pengetahuan dengan tersebarnya buku-buku digital dan artikel jurnal yang ada di portal-portal perpustakaan digital maupun di link jurnal-jurnal ilmiah bereputasi sebagai bahan bacaan. Pada akhirnya mudahnya mendapatkan bahan bacaan yang baik ini harus dijadikan aktivitas wajib dan dilakukan sebagai kebiasaan dan rutinitas yang dirangsang setiap waktu.

Melihat pentingnya peningkatan kemampuan literasi yang salah satu usahanya dengan membiasakan membaca buku ini, pimpinan Kejaksaan Aceh Tengah mempunyai ide untuk menjalin kerjasama dengan Asosiasi Dosen Perguruan Tinggi Islam Aceh Tengah untuk melakukan pendampingan penguatan literasi staf dan jaksa yang ada di lingkungan kerja Kejaksaan Aceh Tengah dengan teknik resume buku digital dengan aplikasi-aplikasi yang mampu merangkum 1 buah buku menjadi 5-15 halaman saja. Kenapa teknik resume buku digital yang dipilih karena tingginya kesibukan keseharian dalam menjalankan tugas pokok sebagai staf maupun jaksa. Sehingga waktu untuk membaca sangat terbatas, dengan alasan ini perlu di berikan metode membaca kilat yaitu dengan membaca rangkuman buku, sehingga dengan waktu yang terbatas mampu menyelesaikan membaca dan dapat megambil kesimpulan isi atau intisari 1 buku perhari.

\section{Metode}

Tahapan penerapan pelatihan peningkatan literasi dengan metode baca kilat di Kejaksaan Negeri Aceh Tengah dilaksanakan berdasarkan permasalahan-permasalahan yang dilihat dan dijumpai pada minat baca pegawai yang menjadi mitra pada program ini. 
Jurnal Pengabdian Masyarakat As-Salam (JPMA)

Vol. 1 No. 2 Juli - Desember 2021: 49 - 56

Yovandi Yazid, Nazamuddin, Muhammad Rizza, Zainul Arifin, Adanan Sitepu, Nur Hidayat, Zulfikri MK, Supinto, Muhammad Jailani, Muhammad Hasyimsyah Batubara

Dalam upaya mencapai tujuan kegiatan penguatan program literasi berbasis metode baca resume buku dengan aplikasi digital, maka rancangan pada kegiatan ini di awali dengan perencanaan (planning), pelaksanaan (action), refleksi (reflection) dan tindak lanjut (follow up).

Kegiatan perencanaan dilakukan melalui aktivitas identifikasi awal yaitu melakukan identifikasi kebutuhan yang meliputi kegiatan: (1) observasi awal yang menghasilkan profil mitra yang menjadi sasaran kegiatan, (2) identifikasi permasalahan yang menghasilkan dokumen permasalahan, dan (3) identifikasi solusi yang menghasilkan alat dan spesifikasi dalam penyelesaian masalah. Kegiatan pelaksanaan dilakukan melalui kegiatan workshop dan pendampingan yang menghasilkan berbagai luaran yang sangat dibutuhkan oleh mitra dalam mengatasi permasalahan yang telah diuraikan. Refleksi dilakukan diakhir kegiatan bertujuan untuk melihat kelemahan dan kekurangan dari kegiatan proses dan hasil yang telah dilakukan serta luaran yang dihasilkan untuk mendapatkan hasil yang maksimal sesuai dengan apa yang direncanakan pada kegiatan ini. Kegiatan tindak lanjut dilakukan untuk memperkuat mitra dalam mengembangkan dan mengimbaskan seluruh program dan kegiatan yang telah diberikan ke jenjang yang lebih luas lagi.

Adapun gambaran metode pelaksanaan kegiatan, seperti tertera pada bagan berikut (Batubara, et al, 2021; Nurmalina, et al, 2021; Zati, et al, 2021):

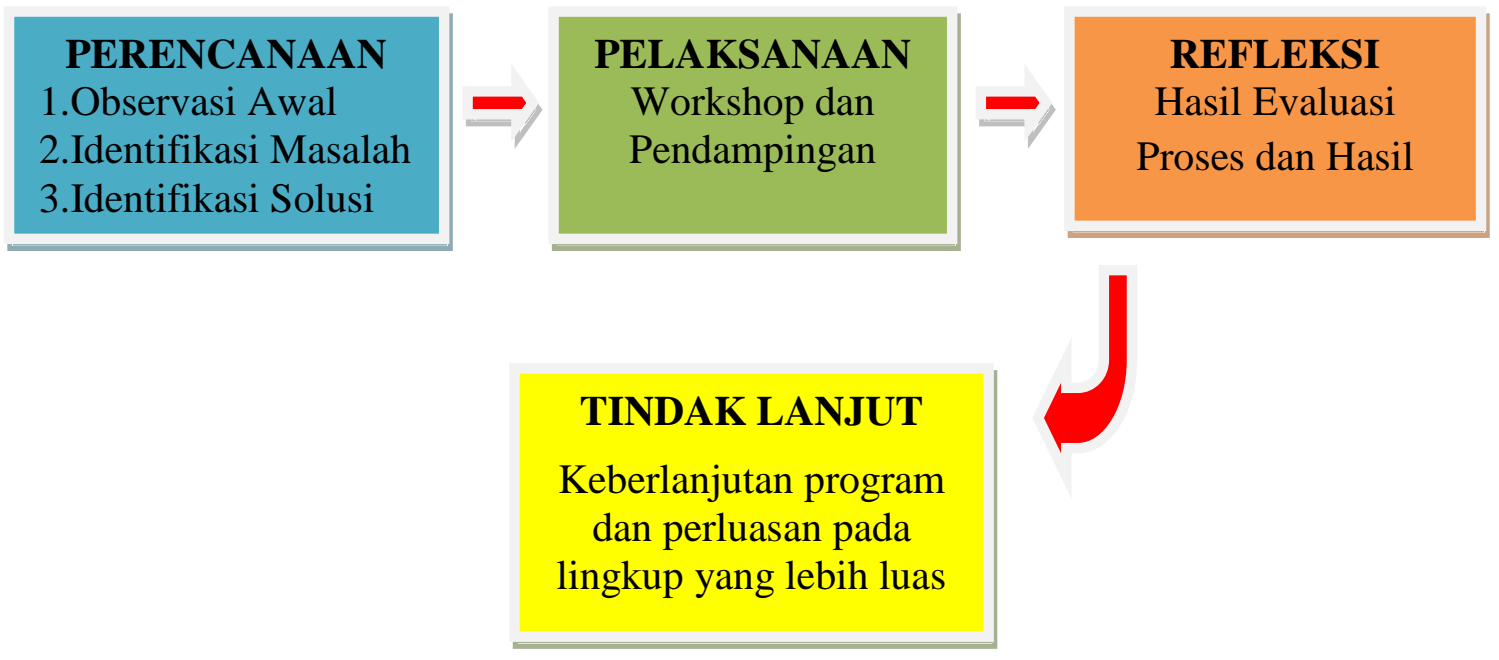

Bagan 1. Alur Pelaksanaan Pengabdian

\section{Hasil dan Pembahasan}

Untuk mengembangkan dan meningkatkan indeks literasi masyarakat, khusnya staf dan jaksa di Kejaksaan Aceh Tengah perlu adanya strategi atau cara yang dilakukan guna menarik dan membangun minat membaca mereka. Salah satu usaha yang dapat dilakukan adalah dengan membaca buku-buku digital yang dapat diresume dengan aplikasi digital juga. Membaca buku digital dapat menghemat waktu dan bisa dilakukan dengan smartphon masing-masing. Sehingga pada pengabdian ini dilakukan pelatihan dalam mengunjungi perpustakaan-perpustakaan digital, dan memperkenalkan aplikasi-aplikasi 
yang dapat digunakan untuk meresume buku tersebut sehingga bisa membaca intisari dari sebuah buku.

\section{Memperkenalkan portal/perpustakaan digital untuk mengunduh buku digital}

Pada tahapan ini diperkenalkan kepada peserta perpustakaan-perpustakaan digital yang dapat dikunjungi, dimana perpustakaan-perpustakaan ini menyediakan buku-buku yang dapat di unduh oleh pembaca. Adapun perpustakaan digital yang diperkenalkan seperti dibawah ini.

I. Buku Digital
a. Project Gutenberg http://www.gutenberg.org/
b. Open Library https://openlibrary.org/
c. OAPEN Library http://www.oapen.org/home
d. Aceh Books http://www.acehbooks.org/
e. Literature.org http://literature.org
f. Feedbooks http://www.feedbooks.com/publicdomain
g. Internet Archive https://archive.org/details/texts
h. manybooks.net
i. bookboon.com
j. getfreeebooks.com
k. ebookdirectory.com
1. ebooklobby.com
m. free-ebooks.net
n. Bookyards.com
o. com.onlinecomputerbooks.qirina.com
p. books.google.com
q. opendirectory.com
r. https://z-lib.org/

II. Artikel Jurnal
a. https://scholar.google.com/
b. https://www.researchgate.net/search
c. https://www.scilit.net/
d. https://www.base-search.net/
e. https://www.neliti.com/id/
f. https://garuda.ristekbrin.go.id/
g. https://www.worldcat.org/
h. https://doaj.org/search/
i. https://app.dimensions.ai/discover/publication 
Jurnal Pengabdian Masyarakat As-Salam (JPMA)

Vol. 1 No. 2 Juli - Desember 2021: 49 - 56

Yovandi Yazid, Nazamuddin, Muhammad Rizza, Zainul Arifin, Adanan Sitepu, Nur Hidayat, Zulfikri MK, Supinto, Muhammad Jailani, Muhammad Hasyimsyah Batubara
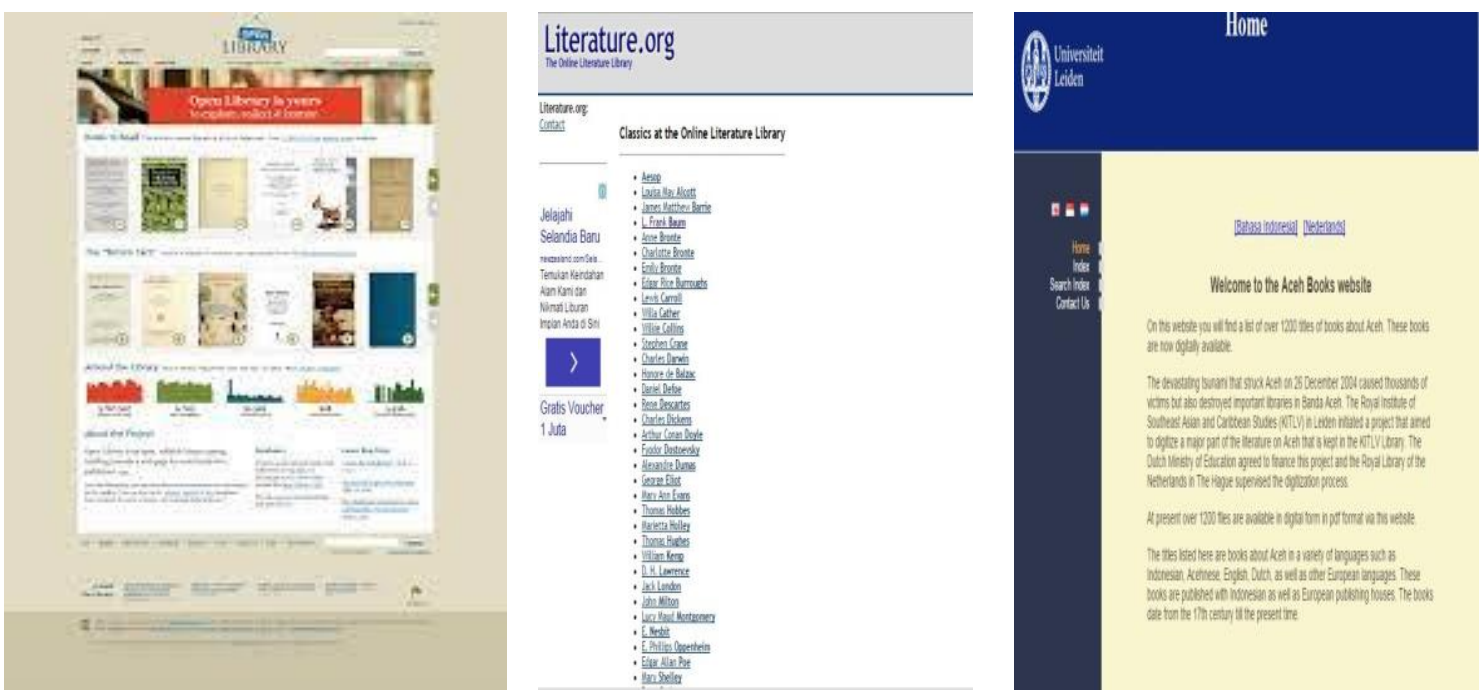

\section{ZLibrary}
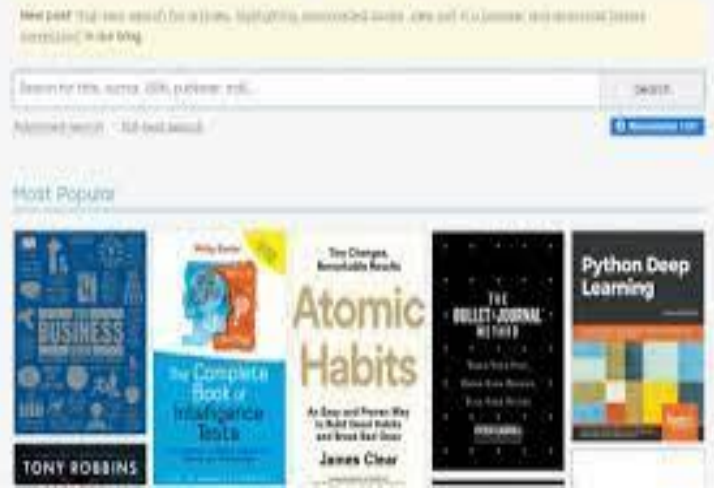

\section{Z-Library}

Gambar 1. Tampilan Perpustakaan Digital

\section{Pengenalan penggunaan aplikasi resume buku digital}

Pada tahapan ini pelatih pengabdian memberikan tutorial untuk mengambil intisari buku dengan menggunakan aplikasi dibawah ini.

a. https://getdigest.com/en

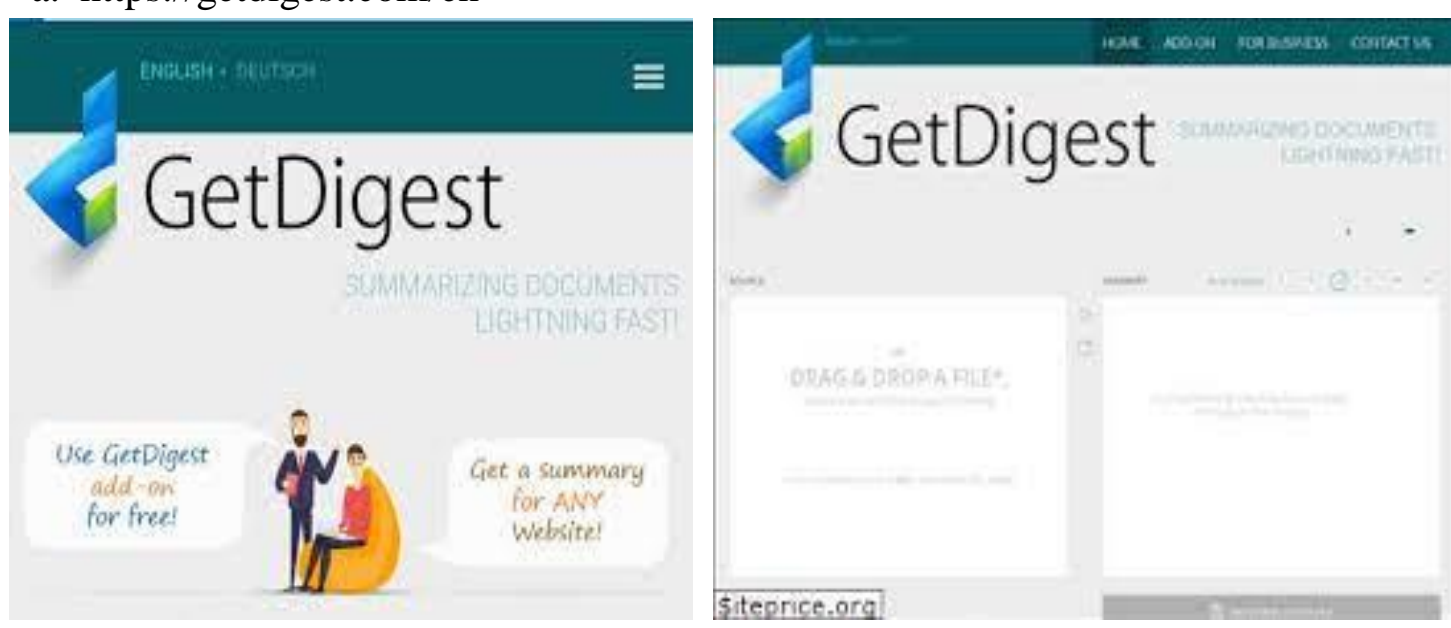

Gambar 2. Tampilan Dan Proses Menggunakan Aplikasi Getdigest.Com 
Yovandi Yazid, Nazamuddin, Muhammad Rizza, Zainul Arifin, Adanan Sitepu, Nur Hidayat, Zulfikri MK, Supinto, Muhammad Jailani, Muhammad Hasyimsyah Batubara

b. https://tldrthis.com/
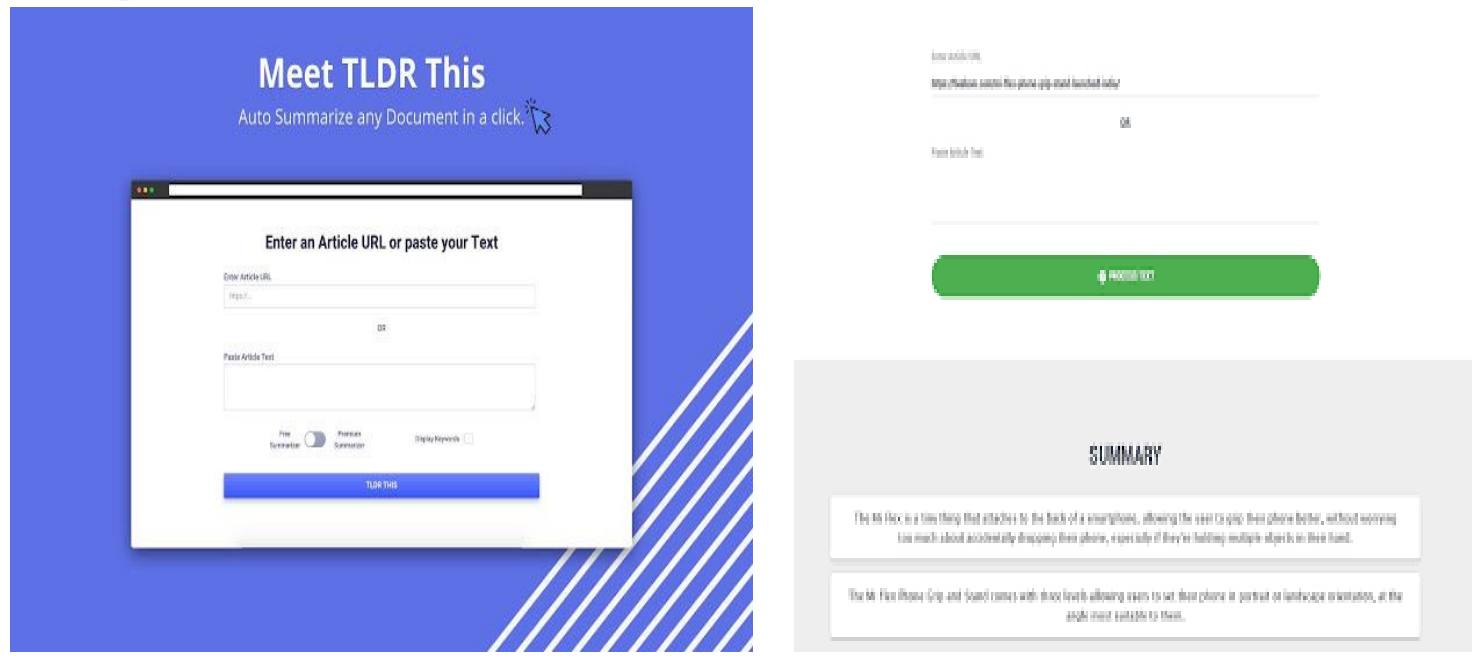

Gambar 3. Tampilan Dan Proses Menggunakan Aplikasi Tldrthis.Com

\section{Sesi latihan dan diskusi tentang pembahasan sebelumnya}
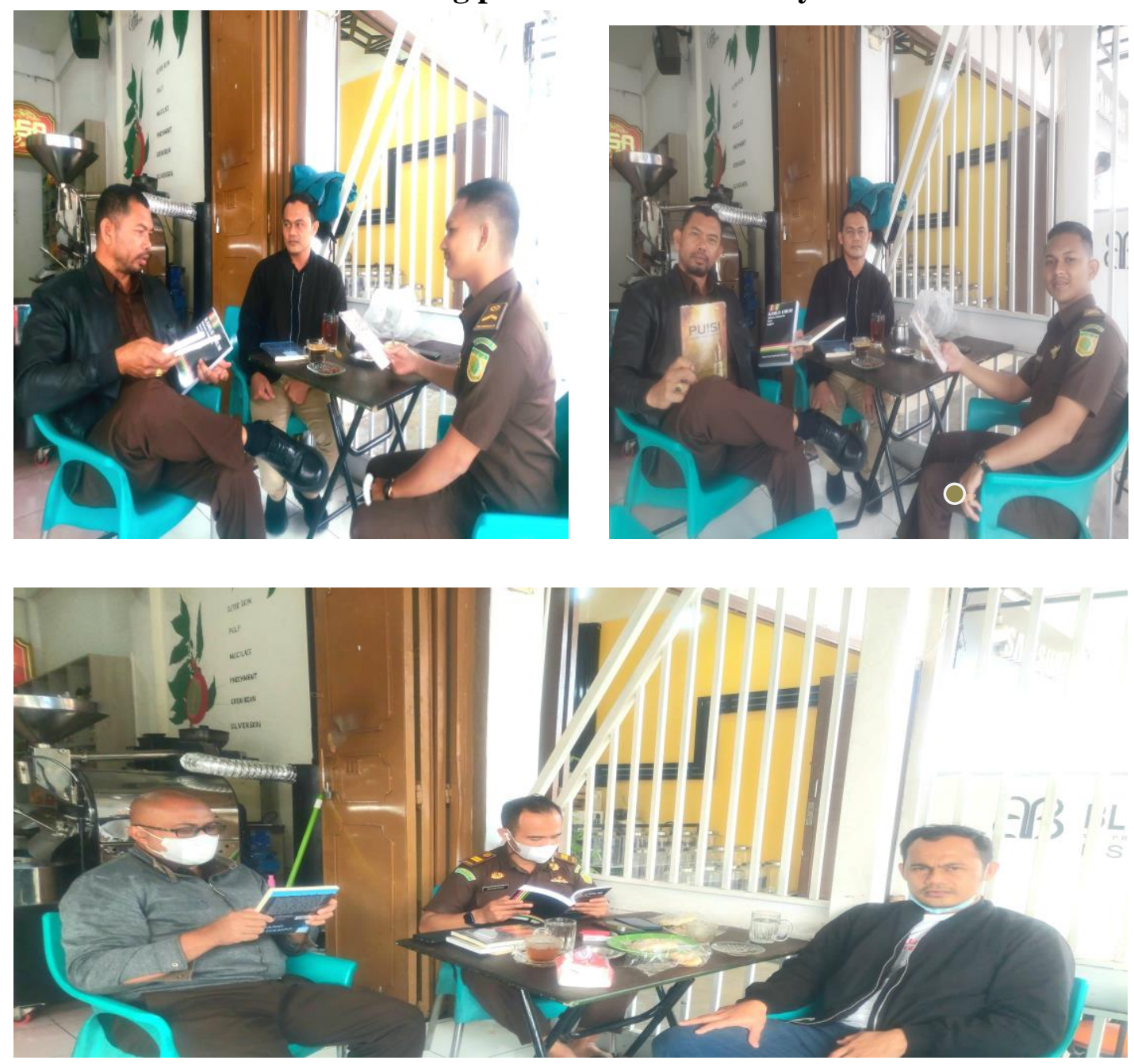

Gambar 3. Diskusi Dalam Pendapingan Pengabdian 
Jurnal Pengabdian Masyarakat As-Salam (JPMA)

Vol. 1 No. 2 Juli - Desember 2021: 49 - 56

Yovandi Yazid, Nazamuddin, Muhammad Rizza, Zainul Arifin, Adanan Sitepu, Nur Hidayat, Zulfikri MK, Supinto, Muhammad Jailani, Muhammad Hasyimsyah Batubara

\section{Kesimpulan}

Dengan kegiatan dan hasil pelatihan pengembangan indeks literasi pegawai Kejaksaan Negeri Aceh Tengah melalui teknik resume buku digital dalam penguatan kelembagaan di era industri 4.0 dan sosiety 5.0 diharapkan mampu menghasilkan dan luaran: (1) membangun kebiasaan membaca walaupun waktu terbatas, (2) tidak terfokus dengan buku fisik dan bisa beralih ke buku-buku format digital, (3) membangun kebiasaan mengunjungi perpustakaan-perpustakaan digital, (4) kemampuan menggunakan aplikasi resume buku digital sehingga mendapatkan intisari satu buku. Kegiatan dan pelaksanaan program pengabdian ini akan dilakukan secara berkelanjutan, dan komprehensif guna meningkatkan indeks literasi dalam membangun kualitas sumber daya manusia Indonesia di tengah-tengah persaingan global yang semakin ketat.

\section{Ucapan Terima Kasih}

Ungkapan terima kasih disampaikan untuk segenap pihak yang terlibat dalam aktivitas pengabdian masyarakat ini, dan khususnya kepada pengelola jurnal pengabdian masyarakat As-Salam (JPMA) yang telah mempublikasikan laporan kegiatan ini.

\section{Daftar Pustaka}

Batubara, M. H. (2018). Bookcase In Coffee Shop Efforts To Strengthen The Literacy Movement From Takengon. University-Community Enggagement October 8-10, $2018,3(1), 612$.

Batubara, M. H., Nurmalina, N., Nasution, A. K. P., Agusmawati, A., \& Maharani, A. (2021). Pelatihan Media Sosial Instagram Untuk Sarana Promosi Ekowisata. JPMA - Jurnal Pengabdian Masyarakat As-Salam, 1(1), 1-8. https://doi.org/10.37249/jpma.v1i1.253

Literasi di Indonesia. 2017. https://student.cnnindonesia.com/edukasi/20170910122629445-240706/mengapa-literasi-di-indonesia-sangat-terendah/ (accessed on September 10, 2018)

Nurmalina, N., Batubara, M. H., \& Nasution, M. K. (2021). Pelatihan Pemantapan Kompetensi Guru Dalam Menghadapi Ukg (Uji Kompetensi Guru). JPMA - Jurnal Pengabdian Masyarakat As-Salam, 1(1), 16-23. https://doi.org/10.37249/jpma.v1i1.255

Zati, V. D. A., Ananda, L. J., \& Batubara, M. H. (2021). Pemanfaatan Buku Bergambar Dwi Bahasa Untuk Penguasaan Kosakata Bahasa Inggris Bagi Anak-Anak Di Lingkungan Xii Kelurahan Tegal Sari. JPMA - Jurnal Pengabdian Masyarakat AsSalam, 1(1), 35-41. https://doi.org/10.37249/jpma.v1i1.266

Internet:

http://www.gutenberg.org/

https://openlibrary.org/

http://www.oapen.org/home

http://www.acehbooks.org/

http://literature.org

http://www.feedbooks.com/publicdomain

https://archive.org/details/texts

https://bookboon.com 
Vol. 1 No. 2 Juli - Desember 2021: 49 - 56

Yovandi Yazid, Nazamuddin, Muhammad Rizza, Zainul Arifin, Adanan Sitepu, Nur Hidayat, Zulfikri MK, Supinto, Muhammad Jailani, Muhammad Hasyimsyah Batubara

https://getfreeebooks.com

https://ebookdirectory.com

https://ebooklobby.com

https://free-ebooks.net

https://Bookyards.com

https://com.onlinecomputerbooks.qirina.com

https://books.google.com

https://opendirectory.com

https://z-lib.org/

https://scholar.google.com/

https://www.researchgate.net/search

https://www.scilit.net/

https://www.base-search.net/

https://www.neliti.com/id/

https://garuda.ristekbrin.go.id/

https://www.worldcat.org/

https://doaj.org/search/

https://app.dimensions.ai/discover/publication 